\title{
Sadder but wiser: A failure to demonstrate that mood influences judgements of control
}

\author{
SUSAN E. BRYSON \\ Dalhousie University \\ BRIAN D. DOAN \\ Victoria General Hospital, Halifax \\ AND \\ PAULA PASQUALI \\ Simon Fraser University
}

\section{ABSTRACT}

A replication and extension of one of Alloy and Abramson's (1979) studies yielded no evidence that mood influences judgements of control in noncontingent button-pressing tasks. It was found that (a) overestimates of control when outcomes are frequent may be due to selective inattention to and/or poor recall of how often outcomes occurred when no response was made; (b) comparable overestimates of control also occur when outcome frequency is low and noncontingency is detected; (c) such overestimates likely do not reflect a self-serving bias, since students in the low density outcome condition were critical of their own performance. The results suggest that the illusion demonstrated in contingency learning studies may be related to expectations of control and to a common tendency to confirm such expectations when presented with evidence of causality (i.e., co-occurrences) between at least some response-outcome pairings. The implications for future research in this area are discussed, and the possibility is entertained that the depressed are not wiser, but more prone to self-attributions of incompetence in certain contingency learning tasks.

Alloy and Abramson (1979) claim in a provocative report that the depressed are wiser than their nondepressed counterparts. In this paper, we focus on some of the complex conceptual and methodological issues raised by that claim. We then present the results of an attempt to replicate and extend their findings and end with a few suggestions for further research on human contingency learning and judgements of control.

Alloy and Abramson (1979) carried out four contingency learning experiments. In each, mildly depressed and nondepressed undergraduates were presented with problems differing both in the degree of contingency between responses and outcomes and in the frequency of outcomes. Responses consisted

We thank Mark Olioff and the reviewers for their helpful comments, and Laurie Gillies for her assistance in conducting the research. The research was supported by a Natural Sciences and Engineering Research Council of Canada grant (\#A8234) to the first author.

Requests for reprints should be sent to Susan E. Bryson, Department of Psychology, Dalhousie University, Halifax, Nova Scotia, Canada, B3H 4JI.

Canad. J. Behav. Sci. / Rev. Canad. Sci. Comp. 16(2), 1984 
of either pressing or not pressing a button and the outcome was the onset of a green light. In some problems, the outcome occurred frequently (e.g., on 75\% of the trials), in others it occurred infrequently (e.g., on $25 \%$ of the trials). In noncontingent problerns, the green light occurred as often when subjects pressed as when they did not press the button (i.e., $75-75,50-50$, or $25-25$ ). In contingent problems, the green light occurred more frequently with one response (pressing or not pressing) than with the other (i.e., 75-0, 75-25, or 75-50). Upon completing the problem, students judged how much control they exerted over the outcomes. The wiser student was viewed as the one whose control judgements more accurately reflected the actual degree of contingency between responses and outcomes.

In general, the students in Alloy and Abramson's (1979) studies were quite accurate in judging the degree of control they exerted. However, unlike the mildly depressed students, nondepressed students overestimated control in two of the noncontingent winning problems and underestimated control in one contingent losing problem. Alloy and Abramson conclude that the nondepressed tend to sacrifice accuracy in favour of enhancing self-esteem, attributing success to themselves and failure to external factors.

It bears emphasizing that in these studies, the effects of mood are confined almost entirely to noncontingent problems in which outcomes occurred frequently or subjects won money. Across a wide range of contingent problems in Experiment 1, depressed and nondepressed students were equally accurate in their judgements of control, and both groups showed a tendency to overestimate control in the one condition (i.e., the $75-50$ problem) that approached noncontingency.

It has been noted in other contingency learning studies (e.g., Allan \& Jenkins, 1980; Neunaber, Wasserman \& O'Hara, 1982; Ward \& Jenkins, 1965) that people do tend to overestimate control as response-outcome contingencies approach zero. The reasons for this have not yet been fully addressed in the literature. One parsimonious explanation is that subjects participate in the typical contingency learning experiment with a bias toward testing and confirming a control hypothesis. In most such studies, the possibility of exercising at least some degree of control is implied at the outset in the instructions. If that is the hypothesis subjects set out to test (i.e., "My responses do make a difference"), it is also the one most likely to be confirmed (see, e.g., Mahoney \& DeMonbreun, 1977; Snyder \& Swann, 1978; Wortman \& Dintzer, 1978).

The trends observed in Alloy and Abramson's (1979) first study lead one to expect that both depressed and nondepressed students would overestimate control in a noncontingent condition. In fact, when noncontingency was introduced in Experiment 2, both groups were equally inaccurate when outcomes occurred infrequently (i.e., the $25-25$ problem). However, a group difference did emerge in the high frequency (i.e., the 75-75) outcome problem: nondepressives - in 
particular nondepressed females - showed a stronger illusion of control than their depressed peers.

Subsequent studies by Abramson, Alloy and their colleagues have yielded equivocal results. A stronger illusion of control for nondepressed students has been demonstrated in noncontingent problems with outcomes of moderate frequency (i.e., 50-50), but only when the students won money. Depressed and nondepressed students were equally accurate in judging control when they lost money, or when they won but were previously exposed to controllable noise (see Alloy \& Abramson, 1982; Alloy, Abramson \& Viscusi, 1981). In one study of judged control in a contingent (i.e., 75-0) problem (Abramson, Alloy \& Rosoff, 1981), depressed and nondepressed students gave comparable judgements of control when instructed in advance that early or late responding might influence the outcomes. When not so instructed, nondepressed students were accurate, whereas depressed students both responded less and underestimated how much control they could have exerted.

Research in other laboratories suggests that the findings from such studies may reflect factors other than egoism on the part of the nondepressed or greater realism among the depressed. Golin, Sweeney and Shaeffer (1981), for example, found that depressed students are prone to make stable, global, internal attributions regarding negative outcomes, and unstable, external attributions for positive outcomes. Similarly, Garber and Hollon (1980) report that depressed subjects do not necessarily view the situation itself as uncontrollable. In their study, both depressed and nondepressed students were equally accurate in distinguishing skill tasks from chance tasks. However, the depressed students underestimated their own, as opposed to others' control in a skilled situation. They believed that control was possible but saw themselves as incompetent. It is possible that the more "accurate" control judgements of the mildly depressed in the Abramson et al. studies reflect, not greater wisdom, but rather a low estimate of their ability to succeed at what they presume is a skilled task.

The present study was designed to replicate and extend Alloy and Abramson's (1979) second experiment. Our purpose was twofold: first, to assess the reliability of their mood effect, and second, to attempt a more powerful test of the sadder but wiser hypothesis. Alloy and Abramson's (1979) Experiment 2 is the only one showing a mood effect where winning or losing money was not part of the manipulation. We wanted to minimize the possibility that self-attributions of incompetence among the depressed would enter into their judgements of contingency and control. Following Alloy and Abramson's procedure closely, students were assigned to depressed and nondepressed groups according to their scores on the Beck Depression Inventory (BDI, Beck, Ward, Mendelson, Mock, $\&$ Erbaugh, 1961). They then were presented with Alloy and Abramson's contingency learning problem, with either high (75-75) or low (25-25) frequency, noncontingent outcomes. 
In addition to questioning the students about control and about their knowledge of the conditional probabilities of the outcomes (i.e., the actual frequency of green light onset when pressing and not pressing a response key), we asked the students to estimate how often it was possible to produce the green light, how well they did relative to what was possible, and how often the green light would have occurred with random responses.

We reasoned that these additional questions might shed further light on the factors that influence judgements of control. If, as Alloy and Abramson claim, the nondepressed are motivated by a self-serving bias, then their estimates of how often they produced the green light should (a) approximate their judgements of what was possible, and (b) be greater than their judgements of what would have happened by chance alone. In contrast, the purportedly wiser, depressed students should judge that both what occurred and what was possible approximated what would have resulted by chance.

The operation of a self-serving bias implies that overestimates of control should be accompanied by a sense of success. Our additional questions allow us to assess this directly. Suppose, for example, that subjects in noncontingent problems not only overestimate control but also believe that they produced fewer outcomes than what was possible, or worse, fewer than would have occurred by chance. Such findings would be consistent with the idea that people are biased toward testing and confirming a control hypothesis. They would pose serious problems, however, for the claim that illusions of control reflect a self-serving bias.

\section{METHOD}

\section{Subjects}

Sixty-four undergraduates, 32 males and 32 females, received credit points toward an introductory psychology course for participating in this experiment. Their ages ranged from 18 to 30 years, with a mean of 19 years. Following Alloy and Abramson (1979), a criterion score of 9 on the BDI was used to assign students to depressed and nondepressed groups. The students also completed the Today Form of the Multiple Affect Adjective Checklist (MAACL. Zuckerman \& Lubin, 1965). The correlation between scores on the BDI and the depression component of the MAACL was .67 $(p<.001)$.

Students were randomly assigned to one of two problem types, with the restriction that both problems were presented to equal numbers of depressed and nondepressed males and females. Table 1 gives the mean BDI and MAACL scores for each group in both problem types (compare with Alloy \& Abramson (1979). Table 4, p. 458). An analysis of variance of the BDI scores yielded no significant main effects of Problem or Sex, nor any interaction of these with Mood. There were two female experimenters. Half of the students in each group were tested by one or the other experimenter to control for possible experimenter effects.

\section{Design and Problem Types}

The experiment was conducted in a 2 (Problem Type) by 2 (Mood) by 2 (Sex) factorial design. The two problems differed in the frequency of outcomes (i.e. . green light onset) but not in the degree of control. For both problems, responses and green light onset were noncontingent. Regardless of 
TABI.F I

Mean BIDI and MAACL scores for nondepressed and depressed males and females in both problem types.

\begin{tabular}{|c|c|c|c|c|c|c|c|c|}
\hline & \multicolumn{8}{|c|}{ Problem and Test } \\
\hline & \multicolumn{4}{|c|}{$25-25$} & \multicolumn{4}{|c|}{$75-75$} \\
\hline & \multicolumn{2}{|c|}{$\mathrm{BDI}$} & \multicolumn{2}{|c|}{$M A \wedge C L$} & \multicolumn{2}{|c|}{ BISI } & \multicolumn{2}{|c|}{ MAACL } \\
\hline & $\overrightarrow{\mathrm{X}}$ & SI) & $\bar{X}$ & SD & $\overline{\mathrm{X}}$ & SD & $\bar{x}$ & SD \\
\hline \multicolumn{9}{|c|}{ Nondepressed } \\
\hline Males & 3.5 & 2.3 & 10.4 & 7.1 & 5.0 & 1.8 & 10.6 & 5.6 \\
\hline Females & 3.0 & 2.0 & 9.9 & 9.9 & 3.8 & 2.3 & 12.8 & 6.0 \\
\hline \multicolumn{9}{|l|}{ Depressed } \\
\hline Males & 12.4 & 1.8 & 13.4 & 10.2 & 12.6 & 4.2 & 16.0 & 6.3 \\
\hline Females & 16.3 & 7.7 & 19.8 & 7.2 & 13.9 & 6.1 & 21.3 & 9.1 \\
\hline
\end{tabular}

whether the students pressed or did not press a button on any given trial, in Problem $1(25-25)$ the green light occurred 25\% of the time, and in Problem 2 (75-75) it occurred 75\% of the time.

\section{Apparatus and Materials}

The apparatus was the same as that described by Alloy and Abramson (1979) except that a Linc 8 computer controlled presentation of the stimuli and recorded the students" responses. A yellow and a green light were positioned on a black display panel in front of the subject. who responded by either pressing or not pressing a spring-loaded button mounted on a separate box.

Pilot testing in our laboratory indieated that in addition to the well-documented primacy and recency effects (see Jenkins \& Ward, 1965), students are very sensitive to patterns of outcomes across trials. That is, not only are judgements of control influenced if a cluster of outcomes happens to occur either at the beginning or end of the series of trials, but students will also identify patterns (e.g. "The light comes on every fourth or fifth trial" $)$ if outcomes are distributed with any regularity across trials. Following Jenkins and Ward (1965), such effects were mininized in the present study by programming cight different random sequences for cach problem type. The only restrictions on randomness were that the green light 1 ) oceurred equally often during the first and last 20 (rials, and 2) never occurred in clusters at any point in the sequence.

The experimental materials consisted of the BDI and the MAACL Today Form. seven judgement and associated certainty scales, and a post-experimental questionnaire. The seales were $100 \mathrm{~cm}$ lines sectioned in the middle, with values of 0 and $100 \%$ at either end. The ends of the Judgement of Control scale were labelled "no control" and "complete control". The ends of the Evaluation of Personal Performance scale were labelled "extremely poorly" and "extremely well", and the other five scales (i.c.. Judged Total Light Onset. Judged Light Onset if Press. Judged Light Onset if Not Press. Estimated Possible Light Onset and Estimated Chance Light Onset) were labelled "never" and "every tinc".

\section{Procedure}

The students were tested individually in one of two adjoining rooms. They were seated at a table in front of the display panel and response box and were observed through a one-way mirror by the experimenter. The procedure and instructions for both problem types were identical. The students first completed the BDI and the MAACL in the absence of the experimenter. They were then instructed to cither press or not press the button on each of 40 . threc-second trials and to learn how much control they had over green light onset. Onset of the yellow light marked the beginning of each trial, and after 
three seconds the green light either appeared or was not presented, independent of whether or not the subject pressed the button. The intertrial interval ranged from 10 to $25 \mathrm{secs}$, with a mean of 15 secs.

Having administered Alloy and Abramson's (1979) instructions, the experimenter left the room and the student completed 40 trials of either the 25-25 or 75-75 noncontingency learning problem. The experimenter then returned to reread the final part of the instructions in which the concept of control is discussed:

Complete control means that the onset of the green light is totally defermined by whether you chose to press or not press. No control means that green light onset has nothing to do with what you do or do not do. In other words, whether or not the green light comes on is a matter of chance or luck. Intermediate degrees of control means that your choice to press or not press influences but does not totally determine green light onset. You might find, for example, that one response produces the green light more often than the other response. Any questions?

The student then completed the seven judgement and accompanying certainty scales.

Unlike Alloy and Abramson, we collected certainty ratings on all judgenents rather than on the judgement of control alone. As no group or problem differences emerged for any of the certainty ratings, they will not be discussed further. In general, students" certainty about their judgements was moderate to high. However, we note that they were more confident when judging the frequency of light onset $(74.5 \%$ to $80.7 \%$ ) than when estimating how much control they exerted $(\bar{X}=59.3 \%)$. what was possible $(\bar{X}=60.9 \%)$, what would have occurred by chance $(\bar{X}=55.8 \%)$. or how well they did $(\bar{X}=57.1 \%)$.

On the Judgement of Control scale, students rated how much control they believed they exerted over onset of the green light. On the Judged Total Light Onset scale, they estimated the overall percentage of trials in which the green light occurred. The next two scales. Judged Light Onset if Press and if Not Press, were included to determine whether the students had the necessary data for computing the conditional probabilities that would yield accurate control ratings. The last three scales. Estimated Possible Light Onset, Evaluation of Personal Performance and Estimated Chance Light Onset, were designed to assess the students' estimates of the best outcome that was possible, how well they did relative to what they believed possible. and how often the green light would have occurred had they responded randomly.

The students then completed the post-experimental questionnaire in which they were asked to describe what evidence led them to conclude that they either had or did not have control, and the hypotheses or strategies they used in solving the problem. Finally, each student was carefully debriefed before lcaving the laboratory.

\section{RESULTS}

\section{Judgement Scales: Control and light onset}

A three-way multivariate analysis of variance (Problem Type $\times$ Mood $\times$ Sex) computed on the seven judgement scales yielded a significant multivariate $F$ for Problem Type only, $F(7,50)=7.58$, Pillais trace criterion $=0.51, p<.001$. Both the multivariate and the univariate main effects of Mood and Sex and all interactions were not significant, thus failing to replicate Alloy and Abramson's (1979) key finding. The results of the univariate tests for Problem Type (i.e., $75 \%$ vs $25 \%$ green light onset) are reported below.

First of all, students' judgements of control did not differ as a function of outcome frequency, $F(1,56)=2.50$, ns. Table 2 gives the mean judged control scores by problem, mood and sex. The means from our experiment and that of Alloy and Abramson are comparable, with one possible exception: the control 


\section{TABLE 2}

Mean judged control scores by problem type, mood and sex.

\begin{tabular}{|c|c|c|c|c|}
\hline & \multicolumn{4}{|c|}{ Problem } \\
\hline & \multicolumn{2}{|c|}{$25-25$} & \multicolumn{2}{|c|}{$75-75$} \\
\hline & $\overline{\mathrm{x}}$ & SD & $\bar{x}$ & SD \\
\hline \multicolumn{5}{|c|}{ Nondepressed } \\
\hline Males & 23.9 & 24.8 & 24.1 & 27.2 \\
\hline Females & 9.9 & 14.2 & 43.3 & 28.5 \\
\hline \multicolumn{5}{|l|}{ Depressed } \\
\hline Males & 43.8 & 37.2 & 50.0 & 27.4 \\
\hline Females & 25.0 & 27.0 & 30.4 & 36.4 \\
\hline
\end{tabular}

ratings of our depressed students, particularly the males, appear more inaccurate than those of Alloy and Abramson's $(1979$, p. 459) depressed groups. Nevertheless, we found no evidence that judgements of control vary as a function of problem type, mood, sex, or any combination thereof.

To facilitate the discussion that will follow, we suggest a comparison of the mean judgements of control from Alloy and Abramson's (1979) Experiment 2 (p. 459) and our replication, against the control ratings from their Experiment 1 (p. 453). In the latter, students estimated control under contingent, high density outcome conditions, and both the nondepressed and mildly depressed were equally accurate. Our findings for students exposed to high density, noncontingent green lights (i.e., the 75-75 problem) seem more consistent with Alloy and Abramson's results in Experiment 1 than do their own from Experiment 2.

Turning now to the estimates of green light onset: the students in both our and Alloy and Abramson's studies were relatively accurate in estimating how often the green light occurred overall and when they pressed the button. However, they tended in both studies to underestimate its frequency when they did not press. In our experiment (though not in Alloy and Abramson's), these underestimates differed significantly across the two problems, $F(1,56)=16.21, p<.001$. Students in our $75-75$ problem were particularly inaccurate in estimating the frequency of green light onset when not pressing. The mean discrepancy between the judged and actual frequency of green lights when not pressing was -27.4 percent. This finding does not appear to be due to differential responding. The mean pressing rates out of 40 trials in the $75-75$ and $25-25$ problems were 24.53 and 24.09 , respectively. An analysis of variance conducted on the pressing rates failed to yield a significant effect of Problem, Mood, Sex, or any combination of these variables.

\section{Additional Judgement Scales}

The mean discrepancy between the students' judgements of how often the green 


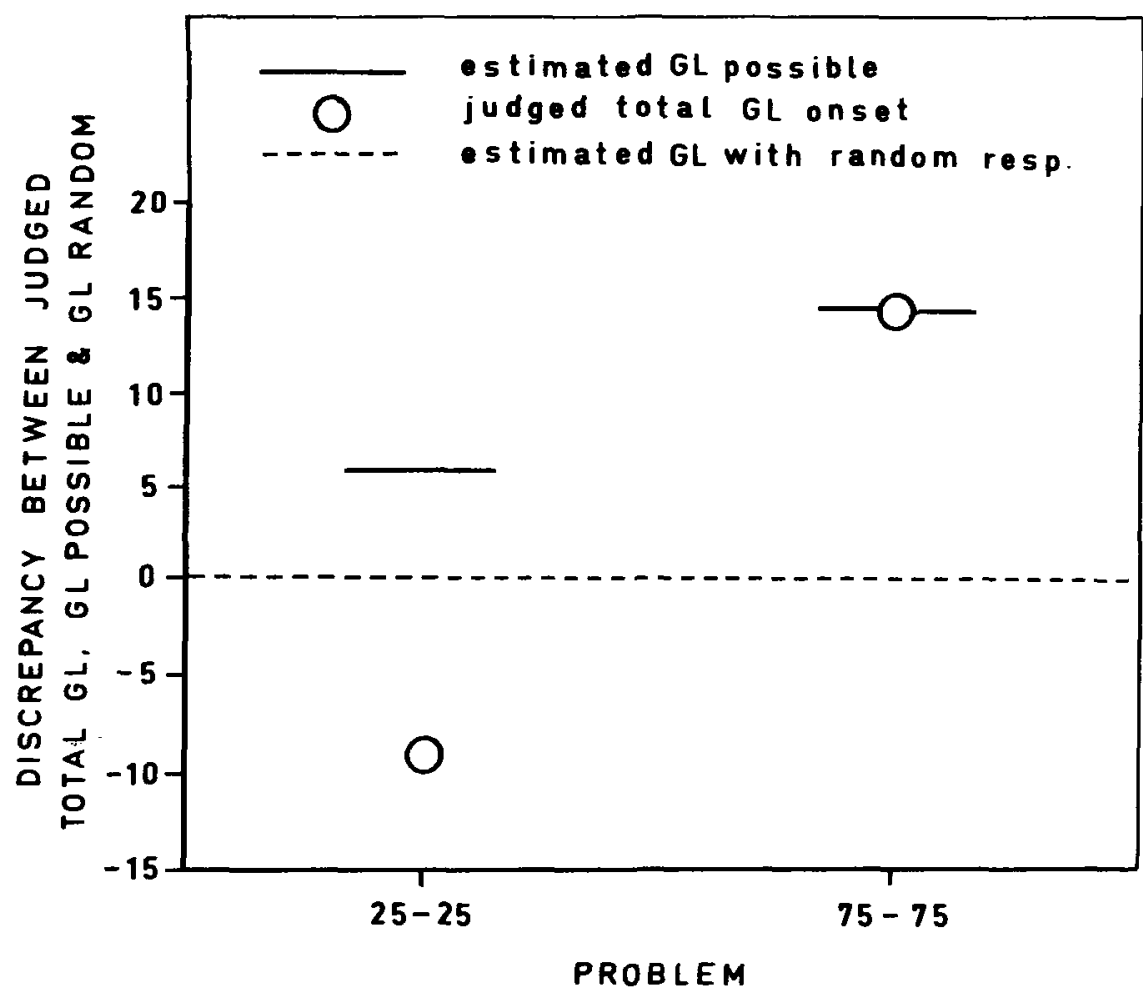

FIGURE I

Mean discrepancy betneen judged total green light onset and estimates of what w'as possible and what would have occurred with random responding as a function of problem type.

light occurred and how often it could have occurred was significantly different for the two problems, $F(1,56)=9.49, p<.003$. The same was the case for the discrepancy between their estimates of how often the green light occurred and how often it would have occurred had they responded randomly, $F(1,56)=$ $26.09, p<.001$. The findings are shown in Figure 1. Students in the 75-75 problem judged that 1) they produced the green light as often as was possible, and 2) it would have occurred far less frequently had they responded randomly. In contrast, students in the 25-25 problem estimated that 1) it was possible to produce the green light more often than they in fact had done, and 2) they would have performed better had they simply decided to press or not press on each trial by flipping a coin.

Finally, the difference between the performance evaluations of the students in the two problems was significant, $F(1,56)=3.70, p<.05$. Those in the $75-75$ problem tended to evaluate their performance more highly $(\overline{\mathrm{X}}=57.44$, s.d. $=$ 
15.74) than did their peers in the $25-25$ problem $(\bar{X}=48.41, s . d .=25.36)$. It may bear noting in this context that the only other univariate analysis that even approached significance concerned the main effect of Mood on performance evaluations, $F(1,56)=3.38, p<.07$. Depressed students tended to be more self-critical $(\overline{\mathrm{X}}=48.63, s . d .=21.40)$ than nondepressed students $(\overline{\mathrm{X}}=58.19$, $s . d .=20.95)$ across both problems.

\section{Post-experimental Questionnaire}

The number of students who judged that they had no control was roughly the same for both problems (i.e., 10 and 11 out of 32 per problem). When asked what convinced them, the typical response was that it didn't matter what they did. In addition to assessing the relative efficacy of simply pressing and not pressing, most also reported that they tried some complex sequence of pressing and not pressing, all to no avail.

Among those with positive control ratings, responses to the post-experimental inquiry appeared to depend on outcome frequency. When asked what convinced them that they had control, 11 of 22 students in the $75-75$ problem responded emphatically that the green light occurred more often when pressing. Of those remaining, six referred to the overall, high frequency of green light onset and five appealed to intuition or their ability to predict. In contrast, responses from students in the $25-25$ problem with positive control ratings were both more varied and speculative. Ten reported that some complex sequence of pressing and not pressing either produced, or would have produced, the green light more often. Only seven believed that the green light occurred more often when they pressed. Three maintained that they must have erred, either by trying to turn the light on rather than keep it off, or because the green light occurred less than $50 \%$ of the time. One assumed that the experimenter was giving the student control from another room. Our overall impression was that these students believed that control was possible and were trying to explain why they had not performed better.

\section{DISCUSSION}

The results of Alloy and Abramson's (1979) and our study are similar in many respects. The mood ratings of our mildly depressed and nondepressed groups are equivalent to theirs. We presented the undergraduates with the same task under similar experimental conditions, and in general, the resulting judgements of control and frequency of green light onset are comparable. However, the present study yielded no evidence that mood influences judgements of control in noncontingent button-pressing situations (see Table 2). Our failure to demonstrate an effect of mood is consistent with Alloy and Abramson's data for contingent problems and with recent findings of Neunaber et al. (1982) for both contingent 
and noncontingent problems. All in all, we feel compelled to conclude that even in noncontingent situations, support for the sadder but wiser hypothesis is at best equivocal.

There is also reason to believe that the results of the present study run contrary to the sadder but wiser hypothesis and rule out the possibility of a Type 2 error. It is not simply that no significant multivariate or univariate effect of mood obtained for any of the judgement scales. If anything, our depressed students were more dysphoric than those in the Alloy and Abramson (1979) study, and their control judgements more inaccurate and more variable than those of the nondepressed students in both studies.

Alloy and Abramson's claim that the sadder are wiser rests on the assumption that overestimates of control occur because the nondepressed are motivated to maintain or enhance self-esteem. The fact is, in both Alloy and Abramson's (1979) Experiment 2 and our replication, the majority of students -- depressed and nondepressed alike - judged that they did have some control over the noncontingently presented green lights. At first blush, one is tempted to interpret this more robust finding as indicating a strong self-serving bias that is unrelated to mood. However, closer scrutiny reveals that some of our findings argue against the operation of a self-serving bias. On the whole, the data seem more consistent with the view that contingency learning experiments of the present type bias people toward testing and confirming a control hypothesis.

Independent of mood, students in our 75-75 problem did tend to evaluate their performance more highly than those in the low density problem. Moreover, they estimated that they produced the green light as often as was possible, and far more frequently than if they had responded randomly. We cannot infer from this. however, that their overestimates of control reflect a self-serving bias, for the evidence suggests a more basic problem. Students in the high density outcome condition underestimated how often the green light occurred when they did not press the button. Many of them also reported afterwards that they believed the green light had occurred more often when they responded. Apparently, when outcomes occurred frequently, students overestimated control because they either failed to notice or did not remember how often the green light came on when they did not respond. Errors of this sort may occur because (a) events (e.g., presses and light onsets) are more salient than nonevents and hence are more "available" (Tversky \& Kahneman, 1974), and (b) the conjunction between events suggests a causal connection (Allan \& Jenkins, 1980). Selective attention to the cooccurrence of two events is precisely what one would expect from someone who is testing a control hypothesis.

Students in the low density outcome condition overestimated control almost as much as those in the 75-75 problem, even though outcomes were infrequent enough that they were able to estimate accurately how often the green light came on both when pressing and not pressing. Again, however, it would be a mistake 
to conclude that this necessarily reflects self-deception in the service of enhanced self-esteem. Students in the 25-25 problem overestimated control regardless of mood, but they also evaluated their own performance more negatively. They judged that it was possible to do far better than they did and that they would have done better had they responded randomly (see Fig. 1).

The findings from the low density outcome condition are consistent with the notion that strong biases exist toward confirming a control hypothesis. The detected absence of response-outcome contingency in the $25-25$ problem obviously was not sufficient to dissuade most subjects that they had some control. Many simply concluded that they performed poorly and that some complex sequence of pressing and not pressing would have yielded more control. Apparently, as long as there is some degree of co-occurrence between responses and outcomes (e.g., the light does come on sometimes when the button is pressed), subjects see grounds for inferring that their responses are sometimes causally effective, and therefore, that they may have exerted some degree of control (c.f., Allan \& Jenkins, 1980).

The precise relationship between prior expectations and subsequent illusions of control remains a matter for further investigation. To date, studies of contingency detection have focused on subjects' conclusions about control after completion of the experimental trials. The present findings suggest that future research would profit by taking into account subjects' expectations about how much, if any, control is possible before exposure to the experimental task.

Following Allan and Jenkins (1980), we further suggest that greater attention is warranted in contingency learning studies to subjects' notions about causal connections between responses and outcomes. However, Allan and Jenkins' strategy of measuring global, retrospective judgements of response-outcome connections may lack sufficient sensitivity. A more powerful approach may be to measure judgements of causality on a trial-by-trial basis (see Ericcson \& Simon, 1980) and relate these to subjects' final estimates of control.

The results of the present study suggest that whatever natural biases we share towards overestimating contingency, causality, or control when responses and outcomes are noncontingent, mild depression does little to eliminate them. In our study, the only mood effect that even approached significance was related to subjects' self-evaluations. Mildly depressed students tended to be more critical of their own performance than were nondepressed students. Given the findings reported here and elsewhere (see, e.g., Garber \& Hollon, 1980), one wonders whether the depressed are less prone to illusions of control or more likely to view themselves as helpless.

\section{RESUME}

Une reprise (et extension) de l'une des études d'Alloy et Abramson (1979) n'a pas confirmé leur allégation voulant que l'humeur influence les jugements de contrôle dans les tâches de pression d'un 
bouton sans contingence. Les résultants montrent que: a) les surestimations du contrôle, lorsque l'effet de la pression se produit fréquemment, peuvent être dues au fait que la fréquence des effets produits sans pression du bouton échappe à l'attention et/ou au rappel; b) des surestimations comparables du contrôle se produisent aussi lorsque la fréquence des effets est basse et que la non-contingence est détectée; c) de telles suresímations ne semblent pas refléter un biais favorable au sujet, étant donné que le sujet critique sa propre performance dans la condition où l'effet ne se produit pas fréquemment. Ces variables suggèrent que l'illustion démontrée dans les études sur l'apprentissage de la contingence peut être liée à des attentes de contrôle et à une tendance commune à voir ces attentes se confirmer lorsque la présentation comporte des indications de causalité (i.e., de co-occurrence) au moins dans certains des couples effet-réponse. La discussion relève les implications de ces données pour les recherches futures en ce domaine et mentionne la possibilité que les personnes déprimées ne sont pas plus sages, mais qu'elles sont plus enclines à s'attribuer de l'incompétence en certaines tâches portant sur l'apprentissage de la contingence.

\section{REFERENCES}

Abramson, L. Y., Alloy, L. B., \& Rosoff, R. (1981). Depression and the generation of complex hypotheses in the judgement of contingency. Behaviour Research and Therapy, 19, 35-45.

Allan, L. G., \& Jenkins, H. M. (1980). The judgment of contingency and the nature of the response alternatives. Canadian Journal of Psychology, 34, 1-11.

Alloy, L. B., \& Abramson, L. Y. (1979). Judgment of contingency in depressed and nondepressed students: Sadder but wiser? Journal of Experimental Psychology: General. 108, 441-485.

Alloy, L. B., \& Abramson, L. Y. (1982). Learned helplessness, depression, and the illusion of control. Journal of Personality and Social Psychology, 42, 1114-1126.

Alloy, L. B., Abramson, L. Y., \& Viscusi, D. (1981). Induced mood and the illusion of control. Journal of Personality and Social Psychology, 41, 1129-1140.

Beck, A. T., Ward, C. H., Mendelson, M., Mock, J., \& Erbaugh, J. (1961). An inventory for measuring depression. Archives of General Psychiatry, 4, 53-63.

Ericcson, K. A., \& Simon, A. (1980). Verbal reports as data. Psychological Review, 87, 215-251.

Garber, J., \& Hollon, S. D. (1980). Universal versus personal helplessness in depression: Belief in uncontrollability or incompetence. Journal of Abnormal Psychology, 89. 56-66.

Golin, S., Sweeney, P. D., \& Shaeffer, D. E. (1981). The causality of causal attributions in depression: A cross-logged panel correlational analyses. Journal of Abnormal Psychology. 90. 14-22.

Jenkins, H. M., \& Ward, W. C. (1965). Judgment of contingency between response and outcome. Psychological Monographs, 79 (1, Whole No. 594).

Mahoney, M. J., \& DeMonbreun, B. G. (1977). Psychology of the scientist: An analysis of problem solving bias. Cognitive Therapy and Research, 1, 229-238.

Neunaber, D. J., Wasserman, E. A., \& O'Hara, M. W. (1982, November). Judgment of contingency and operant responding in depressed and nondepressed college students. Presented at the annual meeting of the Association for the Advancement of Behavior Therapy, Los Angeles.

Snyder, M., \& Swann, W. B. (1978). Hypotheses-testing processes in social interaction. Journal of Personality and Social Psychology, 36, 1202-1212.

Tversky, A., \& Kahneman, D. (1974). Availability: A heuristic for judging frequency and probability. Cognitive Psychology, 5, 207-232.

Ward, W. C., \& Jenkins, H. M. (1965). The display of information and the judgment of contingency. Canadian Journal of Psychology, 19, 231-241.

Wortman, C. B., \& Dintzer, L. (1978). Is an attributional analysis of the learned helplessness phenomenon viable?: A critique of the Abramson-Seligman-Teasdale reformulation. Journal of Abnormal Psychology, 87, 75-90. 
Zuckerman, M., \& Lubin, B. Manual for the Multiple Affect Adjective Checklist. San Diego: Education and Industrial Testing Service, 1065.

First received 18 Mav 1983 